\title{
Effect of auxiliary on hysteresis property of ferroelectric film by aerosol deposition
}

\author{
Kei Sato, Nobuyuki Kobayashi, Koichi Kondo and Tsutomu Nanataki \\ NGK Insulators, LTD., 2-56 Suda-cho Mizuho, Nagoya 467-8530, Japan, \\ Fax: 81-052-872-7537, e-mail: kei-sato@ngk.co.jp
}

\begin{abstract}
Concerning the ferroelectric films produced by AD method, the effects by adding auxiliary agents to injection powder and the effects by grain size were investigated for the purpose of realizing higher ferroelectric property. Ferroelectricity of AD film was found to be improved by adding low melting point auxiliary agents and using calcined powder, and was also found to depend on the grain size of injection powder, and to be improved by increasing the size to an appropriate value. By optimizing the conditions, good ferroelectricity was realized; such as $\mathrm{Pr}$ $=25.4 \mu \mathrm{C} / \mathrm{cm}^{2}$ in the heat treatment at $600{ }^{\circ} \mathrm{C}(63 \%$ of sintered film, calcined powder added with low melting point glass) and $\operatorname{Pr}=38.0 \mu \mathrm{C} / \mathrm{cm}^{2}$ in the heat treatment at $700{ }^{\circ} \mathrm{C}(95 \%$ of sintered film, calcined powder added with $\mathrm{Bi}_{2} \mathrm{O}_{3}-\mathrm{ZnO}$ ).

Key words: aerosol deposition, ferroelectric, calcination powder, auxiliary, grain size
\end{abstract}

1 Introduction

As electronic parts become smaller and more integrated, thick film forming technologies have been actively developed for the functional films on various substrates. As for the piezoelectric substances (ferroelectric substances), in particular, various developments go on for actuators, ultrasonic sensors, etc. For the method of forming piezoelectric film on substrate, generally, screen printing method and thin film method (including sol-gel method and CVD method, etc.) are used. The former is not applied to wide variety of substrates because it requires burning at around $1000^{\circ} \mathrm{C}$ for high density while the latter is not appropriate for forming thick films because the film-forming rate is low $(50-200 \mathrm{~nm} / \mathrm{min})$. Aerosol deposition (AD) method, on the other hand, is characterized by films very dense at room temperature and high film-forming rates (10$30 \mu \mathrm{m} / \mathrm{min}$ ), and the development activities became very active recently. If PZT thick film is formed on SUS substrate by $A D$ method, it is reported that characteristics equivalent to or more than other film-forming methods are realized; such as the piezoelectric constant of $-\mathrm{d} 31=80$ $100 \mathrm{pm} / \mathrm{V}$ in heat treatment at $600^{\circ} \mathrm{C}$ which is roughly as low as a half of sintered substance. ${ }^{1,2}$ This is because large amounts of lattice distortion or defects are included due to plastic deformation of particles in the asdepo film because AD method is a film-forming method by impact solidification, and because such modification is insufficient in the heat treatment at around $800^{\circ} \mathrm{C}$ or lower.

Therefore, the purpose of this report was specified as the production of AD films free of lattice distortion or defect in the heat treatment at lower temperatures and as the realization of higher ferroelectricity. As a measure for such purpose, addition of auxiliary agents to injection powder was studied, which is thought to promote the modification of lattice distortion or defect in heat treatment. Also in order to suppress the introduction of lattice distortion or defects in film forming, optimization of grain size of injection powder was also studied.

\section{Powder Production \& Experiment Methods}

\subsection{Powder Production Method}

For the ferroelectric substances, $0.15 \mathrm{~Pb}(\mathrm{Zn}$, Nb) $\mathrm{O}_{3}-0.85 \mathrm{~Pb}(\mathrm{Zr}, \mathrm{Ti}) \mathrm{O}_{3}$ (hereinafter shown as "PZN-PZT") was used. Powder was produced in the solid phase reaction method by the procedure shown below. The materials $\mathrm{PbO}, \mathrm{ZnO}, \mathrm{Nb}_{2} \mathrm{O}_{5}$, $\mathrm{ZrO}_{2}$ and $\mathrm{TiO}_{2}$ were measured to the specified amounts so that the total weight may be $200 \mathrm{~g}$, and were wet-blended by ball mill. Conditions of ball mill are shown in Table 1. After drying, the blended powder was calcined at $900^{\circ} \mathrm{C}$, and wetcrushed by ball mill. Ferroelectric powder was

Table 1 ball mill condition

\begin{tabular}{|l|l|}
\hline apparatus & ball mill amount \\
\hline pot diameter and volume & $\phi 140 \mathrm{~mm} / 1 \mathrm{l}$ \\
\hline ball diameter and material & $\phi 5-\mathrm{YSZ}$ ball \\
\hline ball weight & $2 \mathrm{~kg}$ \\
\hline disperse media and weight & water $/ 300 \mathrm{~g}$ \\
\hline mixed time & 40 hours \\
\hline mixed time (after calcined) & $5-12$ hours \\
\hline
\end{tabular}

obtained after drying. For the auxiliary

agents on the other hand, two types were discussed, such as $\mathrm{Bi}_{2} \mathrm{O}_{3}-\mathrm{ZnO}^{3}$ and lead zinc borosilicate low melting point glass (IWF-9598 made by $\mathrm{AGC}$ ). Respective melting points are $751^{\circ} \mathrm{C}$ and $648^{\circ} \mathrm{C}$. For $\mathrm{Bi}_{2} \mathrm{O}_{3}-\mathrm{ZnO}, \mathrm{Bi}_{2} \mathrm{O}_{3}$ and $\mathrm{ZnO}$ were measured to specified amounts, wet-blended by ball mill, and crushed to the grain size of 0.5 $\mu \mathrm{m}$ after being calcined at $750^{\circ} \mathrm{C}$. Low melting 
point glass was also wet-crushed so that grain size may be $0.5 \mu \mathrm{m} .1 .0 \mathrm{wt} \%$ of auxiliary agent was added to $\mathrm{PZN}-\mathrm{PZT}$.

\subsection{Auxiliary agent adding method}

Powder added with auxiliary agent was prepared in two ways; such as the blended powder made by mixing PZN-PZT with auxiliary agent by ball mill and the calcined powder crushed by calcination at the specified temperature after mixing. Calcinating temperatures was $850^{\circ} \mathrm{C}$ in the addition of $\mathrm{Bi}_{2} \mathrm{O}_{3}-\mathrm{ZnO}$, and $600^{\circ} \mathrm{C}, 700^{\circ} \mathrm{C}$, $800^{\circ} \mathrm{C}, 900^{\circ} \mathrm{C}$ and $1200^{\circ} \mathrm{C}$ in the addition of low melting point glass. The keep time at calcinating temperature was 2 hours.

\subsection{AD film production method ${ }^{4}$}

Powder obtained was used as injection powder, and films were formed by $\mathrm{AD}$ film-forming equipment. For the substrate, YSZ substrate was used. As for the electrodes, Pt was formed by screen printing, and heat-treated at $1310^{\circ} \mathrm{C}$, thus realizing the thickness of $5 \mu \mathrm{m}$. On this substrate, thick film of $5-6 \mu \mathrm{m}$ was formed as an AD film. Film-forming conditions at the time are shown in Table 2. Heat treatment temperature after forming film were $600^{\circ} \mathrm{C}, 700^{\circ} \mathrm{C}$ and $800^{\circ} \mathrm{C}$. Max temperature was kept for 2 hours. Heat treatment was performed at $600^{\circ} \mathrm{C}$ by printing Au electrode after heat treatment. Size of electrode was $0.8 \mathrm{~mm}$ x $0.5 \mathrm{~mm}$.

\begin{tabular}{|l|l|} 
Table 2 Condition of film forming \\
\hline Carrier Gas & high purity Air \\
\hline Size of Nozzle Orifice & $10 \times 0.5 \sim 10 \times 1.2 \mathrm{~mm}^{2}$ \\
\hline Working Pressure & $80 \sim 2000 \mathrm{~Pa}$ \\
\hline Working Distance & $5 \mathrm{~mm}$ \\
\hline Consumption of carrier gas & $6 \mathrm{~L} / \mathrm{min}$ \\
\hline Deposition Temperature & Room Temperature \\
\hline Nozzle speed & $1.25 \mathrm{~mm} / \mathrm{s}$ \\
\hline
\end{tabular}

\subsection{Evaluation of Powder and AD Films}

Grain size distribution of powder produced was measured by laser diffraction particle size distribution analyzer (HORIBA; LA-700). Micro structure of AD film was observed by using SEM (JEOL; JSM6390LA). Average grain sizes of film were calculated from SEM images. Crystallinity of $\mathrm{AD}$ films was evaluated by X-ray diffraction using $\mathrm{Cu}-\mathrm{K} \alpha$ line. The remanent polarization value (Pr) and coercive electric field $(\mathrm{Ec})$ as the characteristic values showing ferroelectricity were to be evaluated, and was obtained from the hysteresis curve when adding $100 \mathrm{~Hz}$ of triangle wave of $\max +/-200 \mathrm{kV} / \mathrm{cm}$ to films.

\section{Experiment Results and Evaluation}

\section{I Effects by adding auxiliary agent: $\mathrm{Bi}_{2} \mathrm{O}_{3}-\mathrm{ZnO}$}

Micro structure of formed AD film is shown in Fig. 1. In the heat treatment at $700^{\circ} \mathrm{C}$, there were no large differences among PZN-PZT powder, mixed powder and calcined powder. Film grain size at the time was $100 \mathrm{~nm}$ or so. In the heat treatment at $800^{\circ} \mathrm{C}$, however, grains grew largely by calcined powder, and the film grain size became $280 \mathrm{~nm}$.

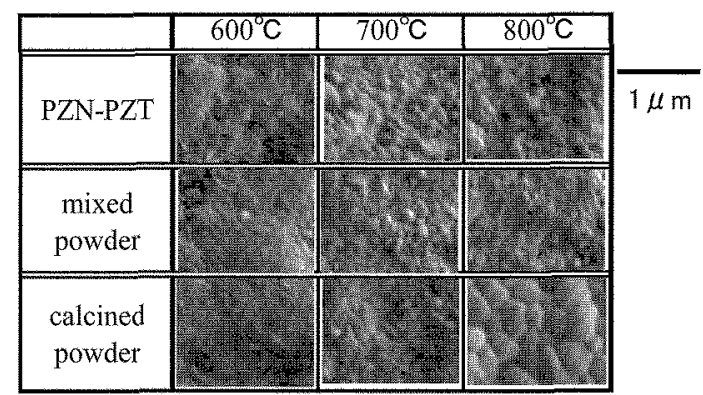

Fig.1 Micro structure of formed AD film

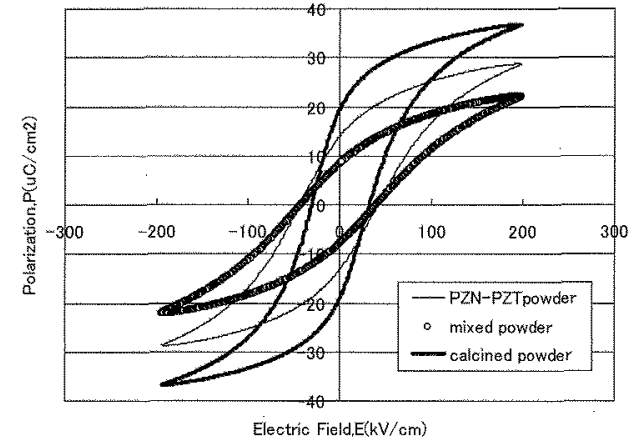

\begin{tabular}{|c|c|c|c|c|}
\cline { 2 - 5 } \multicolumn{1}{c|}{} & Heat treatment & PZN-PZTpowder & mixed powder & calcined powder \\
\cline { 2 - 5 } & $600^{\circ} \mathrm{C}$ & 9 & 5.5 & 11 \\
\cline { 2 - 5 }$\left[\mathrm{uC} / \mathrm{cm}^{2}\right]$ & $700^{\circ} \mathrm{C}$ & 14 & 8 & 20 \\
\cline { 2 - 5 } & $800^{\circ} \mathrm{C}$ & 26 & 25 & 38 \\
\hline \multirow{2}{*}{$\mathrm{Ec}$} & $600^{\circ} \mathrm{C}$ & 43 & 46 & 37 \\
\cline { 2 - 6 }$[\mathrm{kV} / \mathrm{cm}]$ & $700^{\circ} \mathrm{C}$ & 40 & 42 & 32 \\
\cline { 2 - 5 } & $800^{\circ} \mathrm{C}$ & 39 & 40 & 24 \\
\hline
\end{tabular}

Fig2. Hysteresis curve in heat treatment $700^{\circ} \mathrm{C}$ and various of $\mathrm{Pr}$ and $\mathrm{Ec}$

Fig. 2 shows the hysteresis curve of AD film heat-treated at $700^{\circ} \mathrm{C}$ and the changes of Pr. For calcined powder, Pr improved $22 \%$ as compared with PZN-PZT powder in heat treatment at $600^{\circ} \mathrm{C}$, $43 \%$ in heat treatment at $700^{\circ} \mathrm{C}$ and $46 \%$ in heat treatment at $800^{\circ} \mathrm{C}$. Ec was also found to drop as heat treatment temperature rose. As compared with sintered film (burned at $1200^{\circ} \mathrm{C} ; \operatorname{Pr}=42.0$ $\mu \mathrm{C} / \mathrm{cm}^{2}, \mathrm{Ec}=11 \mathrm{kV} / \mathrm{cm}$ ), however, Pr remained as low as $50 \%$ in heat treatment at $700^{\circ} \mathrm{C}$. Ferroelectricity of AD films improved when using the calcined powder to which auxiliary agent was added, and such effects were more remarkable as the heat treatment temperature was higher. In the mixed powders, characteristics dropped. Factors of these results were evaluated as shown below. In the observation of condition inside the films, no difference was seen in density. In the analysis of composition by EPMA, a segregation of $\mathrm{Bi}_{2} \mathrm{O}_{3}$ $\mathrm{ZnO}$ components was detected in the $\mathrm{AD}$ film using mixed powder, and remained even after the heat treatment at $800^{\circ} \mathrm{C}$. No sufficient voltage was applied to ferroelectric substance due to the presence of this segregation as a low dielectric constant phase, thus seemingly reducing the value of $\mathrm{Pr}$. In the asdepo film using calcined powder and $\mathrm{AD}$ films heat-treated at $800^{\circ} \mathrm{C}$, on the other hand, such a segregation in the film as when using mixed powder was not found. Result obtained from XRD of calcined powder also showed that 
$\mathrm{Bi}_{2} \mathrm{O}_{3}-\mathrm{ZnO}$ was sufficiently diffused. We estimated the values of Pr had been improved by a sufficient diffusion of substances even in such a dense film as $\mathrm{AD}$ by heat treatment and a promotion of growth of film grain, by forming films with injection powder in which auxiliary agent is sufficiently diffused.

\subsection{Effects by Auxiliary Agent: Low melting point glass}

Fig. 3 shows the cross-sectional micro structure of $\mathrm{AD}$ film. In the powder calcined by mixed powder and at $700^{\circ} \mathrm{C}$ or lower, dense film was not available. These powders strongly showed the hallow derived from glass component in XRD, and it was found that the low melting point glass particles were not sufficiently melted or diffused. When forming films with glass only, dense film was not available. Judging from this, small amount of glass powder present in the injection grain was suspected to interfere with the plastic deformation and micro crystallization in forming films, thus disabling the formation of dense film.

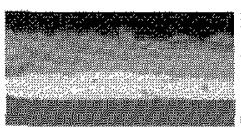

$600^{\circ} \mathrm{C}$

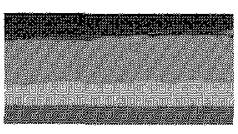

$800^{\circ} \mathrm{C}$

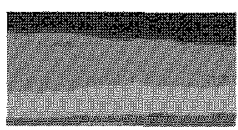

$1200^{\circ} \mathrm{C}$
Fig. 3 the cross-sectional micro structure of $A D$ film using calcined powder at $600-1200^{\circ} \mathrm{C}$

In the calcined powder at $800^{\circ} \mathrm{C}$ or higher, in the meantime, dense film was available. XRD also shows these powders have small hallow, and that low melting point glass was sufficiently diffused in the primary grain of PZN-PZT or grain. Fig. 4 shows the micro structure of film surface. Growth of grain was found to have developed in the heat treatment at $600^{\circ} \mathrm{C}$ lower than that of $\mathrm{Bi}_{2} \mathrm{O}_{3}-\mathrm{ZnO}$.

\begin{tabular}{|c|c|c|c|}
\hline & $600^{\circ} \mathrm{C}$ & $700^{\circ} \mathrm{C}$ & $800^{\circ} \mathrm{C}$ \\
\hline PZN-PZT & & & \\
\hline $\begin{array}{c}600^{\circ} \mathrm{C} \text { calcined } \\
\text { powder }\end{array}$ & & & \\
\hline $\begin{array}{c}800^{\circ} \mathrm{C} \text { calcined } \\
\text { powder }\end{array}$ & & & \\
\hline \hline $\begin{array}{c}1200^{\circ} \mathrm{C} \text { calcined } \\
\text { powder }\end{array}$ & & & \\
\hline $1 \mu \mathrm{m}$ \\
\hline
\end{tabular}

Fig.4 Micro structure of $A D$ film surface

This is because the melting point of glass is lower than that of $\mathrm{Bi}_{2} \mathrm{O}_{3}-\mathrm{ZnO}$. It can be said that the diffusion of substances started at lower temperatures, and the growth of grain was promoted. Fig. 5 shows $\mathrm{Pr}$ of $\mathrm{AD}$ film using each calcined powder heat-treated at $600^{\circ} \mathrm{C}$ and $700^{\circ} \mathrm{C}$ and the changes of Pr. Pr was the highest in the film using the calcined powder at $800^{\circ} \mathrm{C}$, and was improved by $26 \%$ in the heat treatment at $600^{\circ} \mathrm{C}$, and by $48 \%$ in the heat treatment at $700^{\circ} \mathrm{C}$ as compared with $\mathrm{PZN}-\mathrm{PZT}$ powder. In the heat treatment at $700^{\circ} \mathrm{C}$, such an improvement was 51
$\%$ as compared with sintered film (burned at $1200^{\circ} \mathrm{C}$ ). In the calcined powder at $900^{\circ} \mathrm{C}$ or higher, on the other hand, the value of $\operatorname{Pr}$ dropped slightly. This result was evaluated as shown below. In the XRD of calcined powder at $900^{\circ} \mathrm{C}$ or higher, peak derived from the components of low melting point glass, peak of $\mathrm{ZnO}$ and $\mathrm{ZnSiO}_{4}$ in particular, was observed remarkably. Also in the film's EPMA, segregation of $\mathrm{Zn}$ was seen. This made us estimate that deposition of $\mathrm{ZnO}$ had occurred as a different phase derived from glass components if calcined at $900^{\circ} \mathrm{C}$ or higher, and was present in the film as a phase of low dielectric constant, thus lowering the ferroelectric properties.

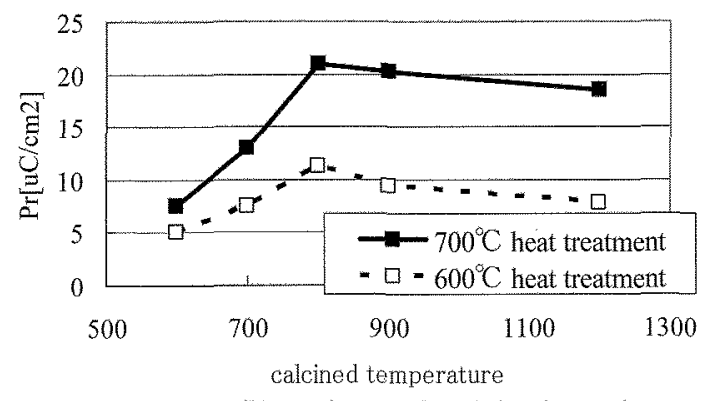

Fig. 5 Pr of $A D$ film using each calcined powder

\subsection{Effects by Powder Grain Size}

We have investigated how ferroelectricity changed, by increasing the grain size in the calcined powder added with both additives. Grain size of powder was adjusted according to the ball mill crush time after calcination, and the grain sizes $0.5,1.0,1.8$ and $2.6 \mu \mathrm{m}$ were obtained. Using these powders, AD films were formed and heat-treated. In the powder of $2.6 \mu \mathrm{m}$, it was hard to realize the required film thickness. Then, films were formed by changing the conditions (including change of nozzle diameter). However, only thing given was the thickness of about $3 \mu \mathrm{m}$.

\begin{tabular}{|c|c|c|c|}
\hline & $600^{\circ} \mathrm{C}$ & $700^{\circ} \mathrm{C}$ & $800^{\circ} \mathrm{C}$ \\
\hline PZN-PZT & & & \\
\hline $\begin{array}{c}\text { calcined po wder } \\
\left(\mathrm{Bi}_{2} \mathrm{O}_{3}-\mathrm{ZnO}\right)\end{array}$ & & & \\
\hline $\begin{array}{c}\text { calcined powder } \\
\text { (glass) }\end{array}$ & & & \\
\hline
\end{tabular}

Fig. 6 Micro structure of film surface using $1.8 \mu \mathrm{m}$ powder

Observation of cross-sectional micro structure of films enabled us to ensure that dense films were seen in powders of all grain sizes. Fig. 6 shows the micro structure of film surface using $1.8 \mu \mathrm{m}$ powder and Fig. 7 shows hysteresis curve. Table 3 shows relation of injection size and film grain size and Pr. Up to $1.8 \mu \mathrm{m}$ in both calcined powders, grain size of film after heat treatment increased as the grain size of powder increased, thus increasing the value of $\mathrm{Pr}$. High values of Pr were obtained, such as $38.0 \mu \mathrm{C} / \mathrm{cm} 2(95 \%$ of sintered 
film) in $700^{\circ} \mathrm{C}$ heat treatment in grain size of 1.8 $\mu \mathrm{m}$ of $\mathrm{Bi}_{2} \mathrm{O}_{3}-\mathrm{ZnO}$ calcined powder, and 25.4 $\mu \mathrm{C} / \mathrm{cm} 2(63 \%$ of sintered film $)$ in $600^{\circ} \mathrm{C}$ heat treatment in grain size of $1.8 \mu \mathrm{m}$ of low melting point glass calcined powder. If powder of grain size of $2.6 \mu \mathrm{m}$ is used, in the meantime, grain size

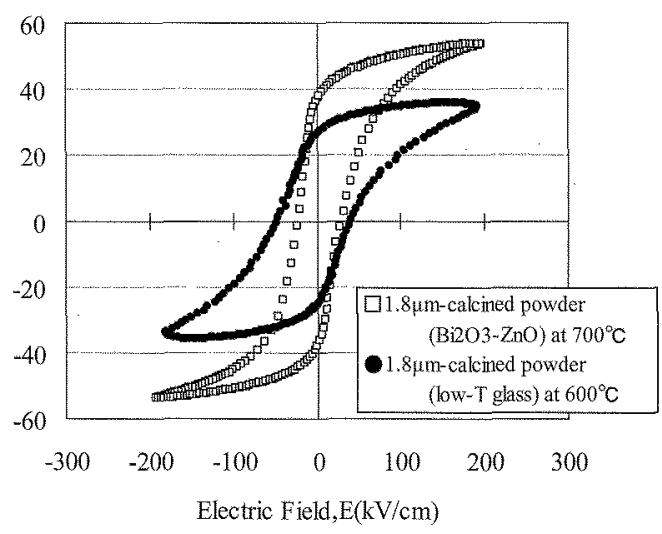

of film decreased, Pr dropped, and Ec increased. Fig.7 Hysteresis curve using $1.8 \mu \mathrm{m}$ injection powder

Table 3 Influence of injection powder size

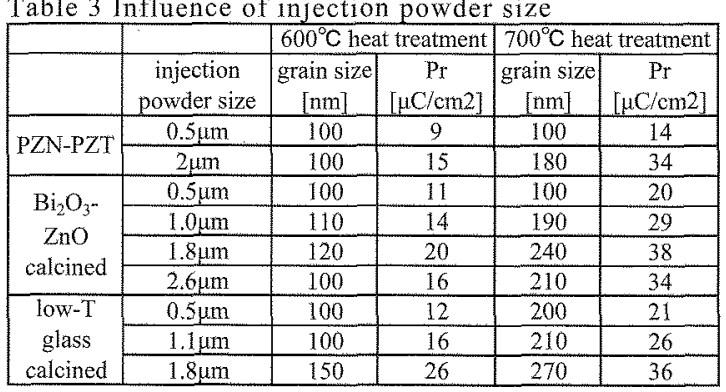

We have also examined, from $X$ ray analysis, the fact that $P r$ value has a peak according to the grain size of powder to be used. Since the film produced by $\mathrm{AD}$ method is accompanied by the plastic deformation or crush of grain in forming films, irregular strains are suspected to occur. In the scope of the half breadth, therefore, effects by crystal's irregular strains are included in addition to the crystallite size. Then, we calculated the crystallite sizes and irregular strains respectively in the asdepo film and heat-treated film by using the formula of Hall. Formula of Hall may be as shown below.

$$
\beta \cos \theta / \lambda=2 \eta \sin \theta / \lambda+1 / \varepsilon
$$

Where, $\beta$ : half breadth, $\theta$ : diffraction angle, $2 \eta$ : crystalline strain, $\lambda$ : wavelength of $X$ ray, $\varepsilon$ : crystallite size.

By this formula, it is possible to calculate the crystallite size and irregular strain separately. Results were shown in. Table 4. There is very small change in crystallite size in time of asdepo according to the grain size of powder. Irregular strain does change on the other hand, and it was shown that, up to $1.8 \mu \mathrm{m}$, strain decreased as injection grain size increased. However, it was shown in $2.6 \mu \mathrm{m}$ that strain increased to the contrary. In $2.8 \mu \mathrm{m}$, films are thought to have been damaged heavily because it was hard to form films. In the area of $1.8 \mu \mathrm{m}$ or less, in the meantime, it was found that films of less strain could be obtained by increasing the grain size. Comparison of these results with the film grain size after heat treatment brought the result that the grain growth is promoted after heat treatment in the asdepo films with less strain. It was also shown that the crystallite size after heat treatment is related to the grain size of film. This made us think that area of less strain in film formation worked as a core under heat treatment, thus promoting the crystallite size and grain growth.

Table 4.Crystallite size and irregular strain by formula of Hall

\begin{tabular}{|c||c|c||c|c|}
\hline $0.5 \mu m$ size & \multicolumn{2}{c||}{$\varepsilon[\mathrm{nm}]$} & \multicolumn{2}{c|}{$\eta$} \\
\hline heat treatment & asdepo & $600^{\circ} \mathrm{C}$ & asdepo & $600^{\circ} \mathrm{C}$ \\
\hline PZN-PZT & 7.1 & 8.2 & 3.8 & 2.8 \\
\hline BZ calcination & 6.5 & 9.1 & 3.1 & 2.4 \\
\hline PZBS calcination & 6.7 & 9.7 & 3.1 & 2.4 \\
\hline
\end{tabular}

\begin{tabular}{|c||c|c||c|c|}
\hline $1.8 \mu m$ size & \multicolumn{2}{|c|}{$\varepsilon[\mathrm{nm}]$} & \multicolumn{2}{c|}{$\eta$} \\
\hline heat treatment & asdepo & $600^{\circ} \mathrm{C}$ & asdepo & $600^{\circ} \mathrm{C}$ \\
\hline PZN-PZT & 6.8 & 10.1 & 3.2 & 1.6 \\
\hline BZ calcination & 8.6 & 13.0 & 2.5 & 1.1 \\
\hline PZBS calcination & 9.2 & 20.1 & 2.5 & 0.7 \\
\hline
\end{tabular}

\begin{tabular}{|c||c|c||c|c|}
\hline $2.6 \mu \mathrm{m}$ size & \multicolumn{2}{c||}{$\varepsilon[\mathrm{nm}]$} & \multicolumn{2}{c|}{$\eta$} \\
\hline heat treatment & asdepo & $600^{\circ} \mathrm{C}$ & asdepo & $600^{\circ} \mathrm{C}$ \\
\hline PZN-PZT & - & - & - & - \\
\hline BZ calcination & 7.8 & 11.3 & 2.6 & 1.6 \\
\hline PZBS calcination & 7.5 & 13.1 & 2.8 & 1.8 \\
\hline
\end{tabular}

\section{Conclusion}

For the purpose of realizing superior ferroelectric properties with less strain and defect on lattice in the heat treatment at lower temperatures in the production of ferroelectric thick films by AD method, we studied the effects by adding auxiliary agents to injection powder and the effects by grain sizes. As a result, ferroelectricity of $A D$ films was found to improve by adding low melting point auxiliary agents and using the powders calcined at appropriate temperatures. It was also found to improve by increasing the grain size of injection powder to an appropriate level. Optimized conditions brought about good ferroelectric properties; such as 25.4 $\mu \mathrm{C} / \mathrm{cm} 2$ (63\% of sintered film, calcined powder added with low melting point glass) of $\operatorname{Pr}$ in the heat treatment at $600^{\circ} \mathrm{C}$, and $38.0 \mu \mathrm{C} / \mathrm{cm} 2(95 \%$ of sintered film, calcined powder added with $\mathrm{Bi}_{2} \mathrm{O}_{3}$ $\mathrm{ZnO}$ ) of $\mathrm{Pr}$ in the heat treatment at $700^{\circ} \mathrm{C}$.

\section{References}

[1]J.Akedo et al: J.Cryst.Growth,235,415(2002)

[2]J.Akedo et al: Appl.Phys.Lett, 77,1710(2000)

[3]K. Tanaka et al:

J.Soc.Mat.Sci.Japan,52(12)1420

[4]J.Akedo et al:

Jpn.J.Appl.Phys, 38,5397(1999)

(Recieved December 6, 2007 ; Accepted November 13, 2008) 